Elsevier Editorial System(tm) for International Journal of Pediatric Otorhinolaryngology Manuscript Draft

Manuscript Number: IJPORL-D-12-00405

Title: A Novel p.Leu213X Mutation in GJB2 Gene in a Portuguese Family

Article Type: Case Report

Keywords: novel mutation; GJB2 gene; connexin 26; deafness; sensorineural; hearing impairment.

Corresponding Author: PhD Helena Caria,

Corresponding Author's Institution: BioFIG, FCUL

First Author: Ana Cláudia Gonçalves, Dr

Order of Authors: Ana Cláudia Gonçalves, Dr; Joana Chora, Dr; Tiago D Matos, Dr; Assunção O'Neill, Dr; Pedro Escada, Dr; Graça Fialho, Professor; Helena Caria, PhD 


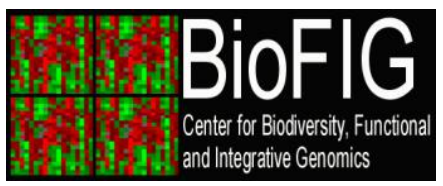

A novel p.Leu213X mutation in GJB2 gene in a Portuguese family

Dear Sirs,

Herewith we are submitting an Article, focused on a new mutation found in the GJB2 gene. This mutation, p.Leu213X, introduces a premature STOP codon avoiding the formation of the functional connexin 26 protein and in the present study was found in compound heterozygosity with another GJB2 mutation already identified (c.333-334delAA), being this genotype responsible for the hearing impairment observed in the two patients.

All the co-authors have been involved in the study and have other publications in the field of Hereditary Deafness published in different journals as Genetics Research International, Am J Med Genet, Hear Research., Int J Ped Otorhinolaryngology, Eur J Hum Genet, J Med Genet.

The corresponding author is:

Helena Caria (helena.caria@ess.ips.pt);

Phone: +351919661584

Fax number: + 351265709392 .

We would like to inform that there is no conflict of interest regarding this study.

Thanking you in advance for your prompt attention to our submission.

Best regards,

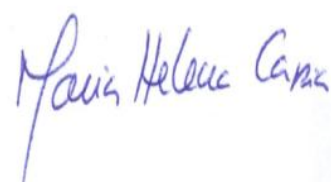

Helena Caria

Deafness Genetics Research Group

Center for Biodiversity, Functional and Integrative Genomics (BioFIG)

Faculty of Sciences University of Lisbon 


\section{A Novel p.Leu213X Mutation in GJB2 Gene in a Portuguese Family}

Gonçalves, A.C. ${ }^{1}$; Chora, J. ${ }^{1}$; Matos, T.D. ${ }^{1}$; O’Neill, A. ${ }^{2}$ Escada, P. ${ }^{2}$; Fialho, G. ${ }^{1}$ and Caria, H. ${ }^{1,3}$

${ }^{1}$ BioFIG, Center for Biodiversity, Functional and Integrative Genomics, University of Lisbon, C2, Faculty of Science of the University of Lisbon Campus, 1749-016 Lisbon, Portugal; ${ }^{2}$ ENT Service, Centro Hospitalar de Lisboa Ocidental EPE, Hospital Egas Moniz, ${ }^{3}$ School of Health, Polytechnic Institute of Setúbal, Largo Defensores da República, 1, 2910-470 Setúbal, Portugal

Corresponding author: Helena Caria (helena.caria@ess.ips.pt; phone: +351919661584; Fax: +351 265709 392; Adress: School of Health Polytechnic Institute of Setúbal (ESS-IPS), Largo Defensores da República, 1, 2910-470 Setúbal, Portugal)

Conflict of Interest:

There is no conflict of interest 
Abstract

Introduction: Hearing loss is the most common sensory disability and is present in about 1.9 per 1000 infants at birth. The DFNB1 locus (13q11-q12) includes the genes GJB2, coding for connexin 26, and GJB6, encoding connexin 30. More than 100 mutations have been identified associated with autosomal dominant and recessive hearing loss in the GJB2 gene.

Objectives: The aim of the present study was to identify the genetic etiology of deafness in two Portuguese individuals, presenting nonsyndromic sensorineural moderate and severe hearing loss, respectively.

Patients and Methods: The individuals were evaluated in both ears by pure tone audiometry and blood samples were collected after written informed consent was signed. DNA extraction and PCR amplification of GJB2 coding region followed standard methodologies. PCR products were automatically sequenced in both directions.

Results:We identified a novel mutation, c.638T>A (p.Leu213X), in GJB2 gene. This nonsense mutation was found in both siblings, and was inherited from their hearing father. Molecular analysis showed that the two siblings were also heterozygous for c.333-334delAA, a previously described GJB2 deletion. This novel mutation was not found in a random control sample of 480 individuals that were screened for coding region of GJB2 gene. p.Leu213X mutation identified in this study for the first time changes the codon 213, coding for a highly conserved and slowly evolving residue of connexin 26 , localised to the C-terminus domain of the protein, to a stop codon, leading to the deletion of the last 14 amino acids of the protein.

Conclusion: We can conclude that the etiology of deafness in these individuals is due to the GJB2 genotype involving the c.333-334delAA deletion and the novel p.Leu213X mutation in compound heterozygosity.

Key-words - novel mutation, GJB2 gene, connexin 26, deafness, sensorineural, hearing impairment 


\section{Introduction}

Clinically significant hearing loss (HL) is present in at least 1.9 per 1000 infants at birth and the prevalence rises to at least 2.7 per 1000 by the age of four [1]. HL may be due to genetic and/or non-genetic (environmental) factors. Most hereditary HL is inherited as a simple Mendelian trait and is nonsyndromic (70\%), being classified as sensorineural when it is caused by problems in the inner ear, cochlear nerve, and/or central auditory pathway [2]. Nonsyndromic sensorineural hearing loss (NSSHL) is predominantly inherited in an autosomal recessive pattern (DFNB loci). The DFNB1 locus, at chromosome 13q11-q12, includes the GJB2 and GJB6 genes, which encode connexin $26(\mathrm{Cx} 26)$ and connexin 30 (Cx30), respectively. These connexin proteins are co-expressed and co-localised in the cochlea, where they are constituents of the cochlear gap junction systems, which are thought to have a role in the recirculation of $\mathrm{K}^{+}$contributing to cochlear homeostasis $[3,4,5]$, and might also be important for $\mathrm{Ca}^{2+}$ signalling [6] and the intracellular diffusion of large cationic molecules [7].

GJB2 gene is about 5500 bp length with 2 exons, of which only one contains the coding region [8]. More than 100 different mutations have been identified in association with autosomal dominant and recessive HL in this gene [8]. Three nonsyndromic recessive mutations, c.35delG, c.167delT and c.235delC have been found at high frequency in Caucasian, Ashkenazi Jewish, and Asian populations, respectively [9].

\section{Methods}

We studied one Portuguese family, composed of two hearing-impaired siblings with HL, aged 11 and 15 (proband) years and their normal hearing parents (fig. 1A). Each affected individual was clinically evaluated to ensure that the HL was not syndromic neither a result of infection, acoustic trauma, ototoxic drugs or premature birth. None of the patients had undergone cochlear implantation.

Written informed consent was obtained from siblings and parents prior to blood sampling. Hearing levels were determined by pure-tone audiometry with a diagnostic audiometer in a soundproof room. The level of HL was classified, following the European 
Working Group on Genetics of Hearing Impairment [10], as mild (21-40 dB), moderate (41-70 $\mathrm{dB})$, severe (71-95 dB), or profound (>95 dB), from an average at 500,1000, 2000 and $4000 \mathrm{~Hz}$ in the better ear. Total genomic DNA was extracted from peripheral blood using the JetQuick Blood and Cell Culture Kit (GENOMED), according to the manufacturer's instructions. PCR amplification of GJB2 coding exon was made using primers $2 \mathrm{AF}$ and $2 \mathrm{BR}$ described previously [11]. After direct bidirectional sequencing electrophoretograms were evaluated by visual inspection and pairwise alignment to reference sequences using NCBI's BLAST (Basic Local Alignment Search Tool) [12]. A random control sample composed of 480 Portuguese individuals was also screened for the coding region of GJB2 gene.

\section{Results}

Pure tone audiometry showed bilateral, sensorineural moderate and severe HL in the proband (individual II:1) and his sibling (individual II:2), respectively (fig. 1D,E). Both parents had normal hearing (fig. 1B,C). A novel variant, c.638T>A (p.Leu213X) was found through molecular genetic analysis in the two siblings in compound heterozygosity with the c.333334delAA previously described deletion. The deletion c.333-334delAA (fig. 2A,B) was inherited from the mother, who is heterozygous for this mutation. The novel mutation p.Leu213X (fig. 2C,D) found in both siblings, was later identified in their father, in heterozygosity. This new mutation was not present in the random control sample of 480 Portuguese individuals that were screened for coding region of GJB2 gene.

\section{Discussion}

Mutations in GJB2 are the most common cause of nonsyndromic, autosomal recessive, hereditary HL, and may account for 10-40\% of all congenital HL depending upon ethnicity [9]. The recessive deletion c.333-334delAA [13] causes a frameshift which results in chain termination after an additional novel amino acid, truncating about half of the protein. This is the first time that this mutation is reported in Portuguese HL patients. 
The novel recessive mutation p.Leu213X, found in this study, creates a premature STOP codon by changing the codon 213 (TTG) which codes for a leucine, for a STOP codon (TAG). This mutation leads to the deletion of the last 14 amino acids of the protein. The Leu213 amino acid residue is localised to the C-terminus domain of the protein. The residues in the intracellular loop region and C-terminus are very different among different connexins and are hence thought to be responsible for regulation. These residues could thus impart unique properties to the various connexin molecules [14]. According to ConSeq [15] the mutation p.Leu213X affects a highly conserved residue that has evolved slowly (fig. 3).

Previously to this study, seven other missense/nonsense mutations were found in the Cterminus of Cx26 [16]. Interestingly, one of those mutations, identified in French patients [17], is also a nonsense mutation, p.Cys211X, occurring close to p.213LeuX and eliminating the conserved amino acid residues 212 and 213 as well as the remnant of the C-terminus of the protein.

\section{Conclusions}

Considering all this, we can conclude that the HL of the two Portuguese siblings is most probably due to the presence of the c.333-334delAA deletion and the p.Leu213X novel mutation, in compound heterozygosity. However, the functional characterization of the p.Leu213X nonsense mutation should be performed in order to investigate the effect of the mutation on the protein, and to provide insight on the role of the conserved 213Leu residue and subsequent amino acid residues for the normal Cx26 function. 


\section{Legends}

Figure 1 - Pedigree of the family analysed in this study (A). Representative audiograms of individual I:2 (B), individual I:1 (C), individual II:1 (D) and individual II:2 (E) showing puretone audiometry results for air conduction bilaterally. Circles in blue represent the right ear; crosses in red represent the left ear.

Figure 2 - Partial sequence of an electrophoretogram showing (A) wild-type sequence and (B) the c.333-334delAA heterozygous deletion (the arrow). Partial sequence of an electrophoretogram showing (C) the wild-type sequence and (D) the novel mutation identified in this study, p.Leu213X, in heterozygosity (arrow).

Figure 3 - Schematic representation of the $\mathrm{Cx} 26$ protein showing the two mutations identified in this study. The extent of amino acid conservation is colour-coded, with residues shown in shades of blue (1-2) not conserved and rapidly evolving. Residues in white (3-6) show an average degree of conservation and residues in shades of red (7-9) are highly conserved and are slowly evolving. The degree of conservation of the polymorphic residues was analysed using ConSeq [15], the sequence only variant of Rate4Site, an algorithmic tool for the identification of functional regions in proteins. Figure adapted from [14]. 


\section{Referencies}

[1] Petersen MB, Grigoriadou M, Economides J, Kokotas H. Compound heterozygosity of the novel c.292C>T (p.R98W) and the c.35delG GJB2 mutations in postlingual, non-syndromic, sensorineural deafness. Int J Pediatr Otorhinolaryngol 2012; 76:549-551.

[2] Ito T, Noguchi Y, Yashima T, Ohno K, Kitamura K. Hereditary Hearing Loss and Deafness Genes in Japan. J Med Dent Sci 2010; 57:1-10.

[3] Kikuchi T, Adams JC, Miyabe Y, So E, Kobayashi T. Potassium Ion Recycling Pathway Via Gap Junction Systems in the Mammalian Cochlea and its Interruption in Hereditary Nonsyndromic Deafness. Medical Electron Microscopy. 2000; 33(2):51-56.

[4] Kikuchi T, Kimura RS, Paul DL, Adams JC. Gap junctions in the rat cochlea: immunohistochemical and ultrastructural analysis. Anat Embryol (Berl). 1995;191(2):101-118.

[5] Kikuchi T, Kimura RS, Paul DL, Takasaka T, Adams JC. Gap junction systems in the mammalian cochlea. Brain Res. 2000;32(1):163-166.

[6] Sun J, Ahmad S, Chen S, Tang W, Zhang Y, Chen P, Lin X. Cochlear gap junctions coassembled from $\mathrm{Cx} 26$ and 30 show faster intercellular $\mathrm{Ca}^{2+}$ signaling than homomeric counterparts. Am J Physiol. 2005; 288(3):613-623.

[7] Meşe G, Valiunas V, Brink PR, White TW. Connexin26 deafness associated mutations show altered permeability to large cationic molecules. Am J Physiol. 2008; 295(4):966-974.

[8] Falah M, Houshmand M, Akbaroghli S, Mahmodian S, Ghavami Y, Farhadi M. Profile of Iranian GJB2 Mutations in Young Population with Novel Mutation. Iran J Basic Med Sci. 2011; 14(3):213-218. 
[9] Tang H-Y, Fang P, Ward PA, Schmitt E, Darilek S, Manolidis S, Oghalai JS, Roa BB, Alford RL. DNA Sequence Analysis of GJB2, Encoding Connexin 26: Observations From a Population of Hearing Impaired Cases and Variable Carrier Rates, Complex Genotypes, and Ethnic Stratification of Alleles Among Controls. Am J Med Genet. 2006; 140A:2401-2415.

[10] http://audiology.unife.it/www.gendeaf.org/hear/infoletters/Info_02.PDF - European Working Group on Genetics of Hearing Impairment. Web site. Accessed April 30.

[11] Matos TD, Simões-Teixeira H, Caria H, Rosa H, O’Neill A, Fialho G. The Controversial p.Arg127His Mutation in GJB2: Report on Three Portuguese Hearing Loss Family Cases. Genet Test Mol Biomarkers. 2010; 14:141-144.

[12] Altschul SF, Madden TL, Schäffer AA, Zhang J, Zhang Z, Miller W, Lipman DJ. Gapped BLAST and PSI-BLAST: a new generation of protein database search programs. Nucleic Acids Res. 1997 25:3389-3402.

[13] Kelley PM, Harris DJ, Comer BC, Askew JW, Fowler T, Smith SD, Kimberling WJ. Novel Mutations in the Connexin 26 Gene (GJB2) That Cause Autosomal Recessive (DFNB1) Hearing Loss. Am. J. Hum. Genet. 1998; 62:792-799.

[14] Mani RS, Ganapathy A, Jalvi R, Srisailapathy CRS, Malhotra V, Chadha S, Agarwal A, Ramesh A, Rangasayee RR, Anand A. Functional consequences of novel connexin 26 mutations associated with hereditary hearing loss. Eur J Hum Genet. 2009; 17:502 - 509.

[15] http://conseq.tau.ac.il/ - The ConSeq Server. Web site. Accessed May 172012. 
[16] Stenson PD, Mort M, Ball EV, Howells K, Phillips AD, Thomas NST, Cooper DN. The Human Gene Mutation Database: 2008 Update. Genome Med. 2009; 1:13.

[17] Feldman D, Denoyelle F, Chauvin P, Garabédian E-N, Couderc R, Odent S et al. Large Deletion of the GJB6 Gene in Deaf Patients Heterozygous for the GJB2 Gene Mutation: Genotypic and Phenotypic Analysis. Am. J. Hum. Genet. 2004; 127A:263-267. 
A

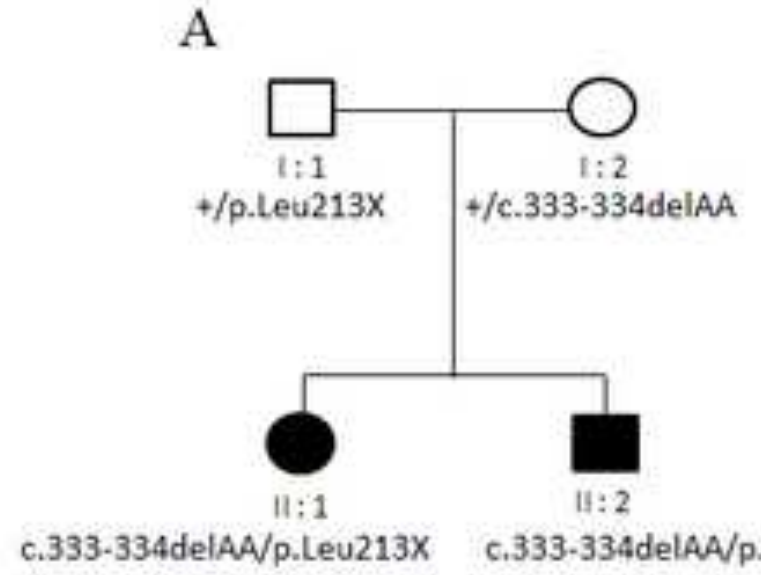

B
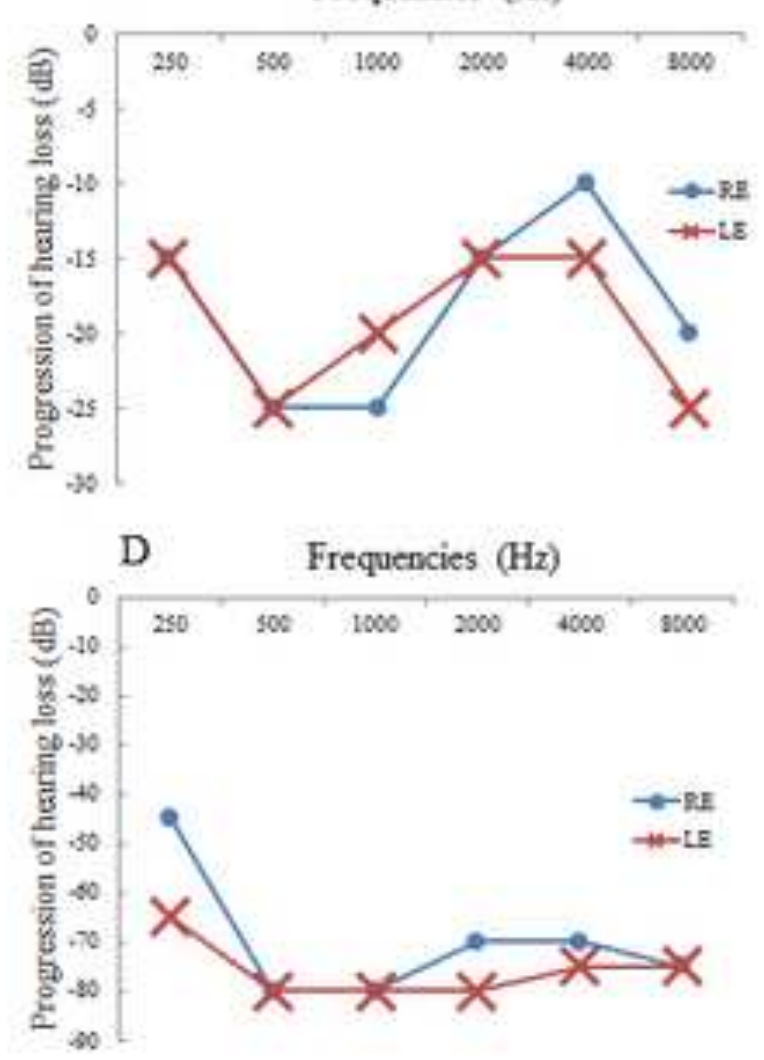

C Frequencies $(\mathrm{Hz})$
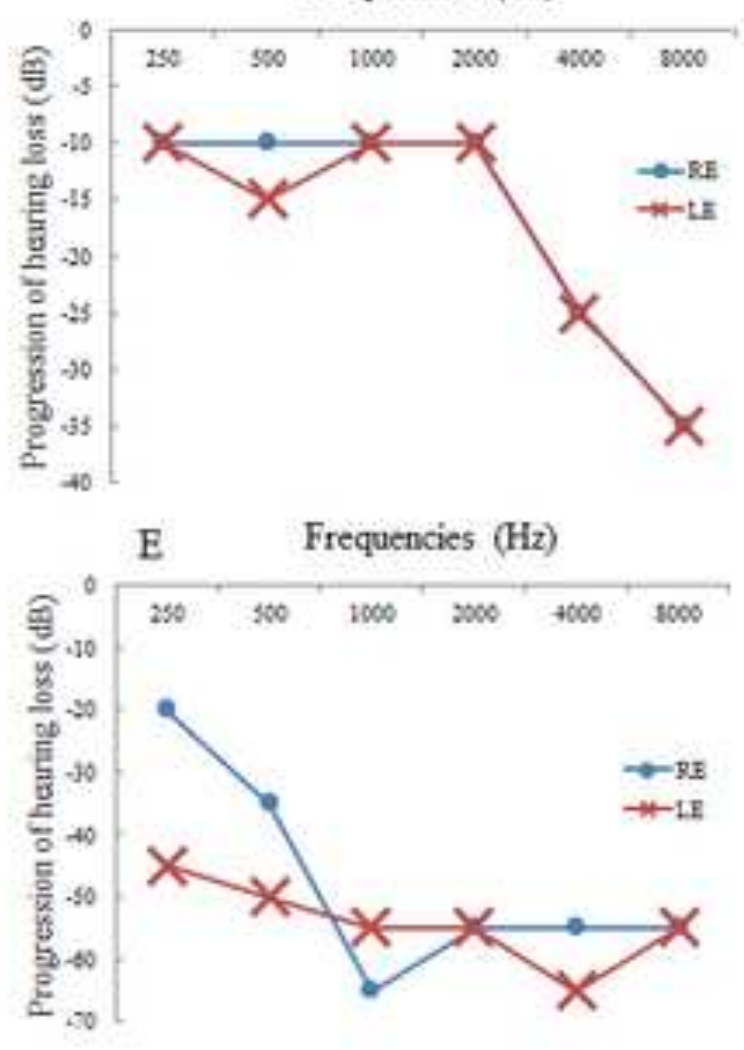
A G G G

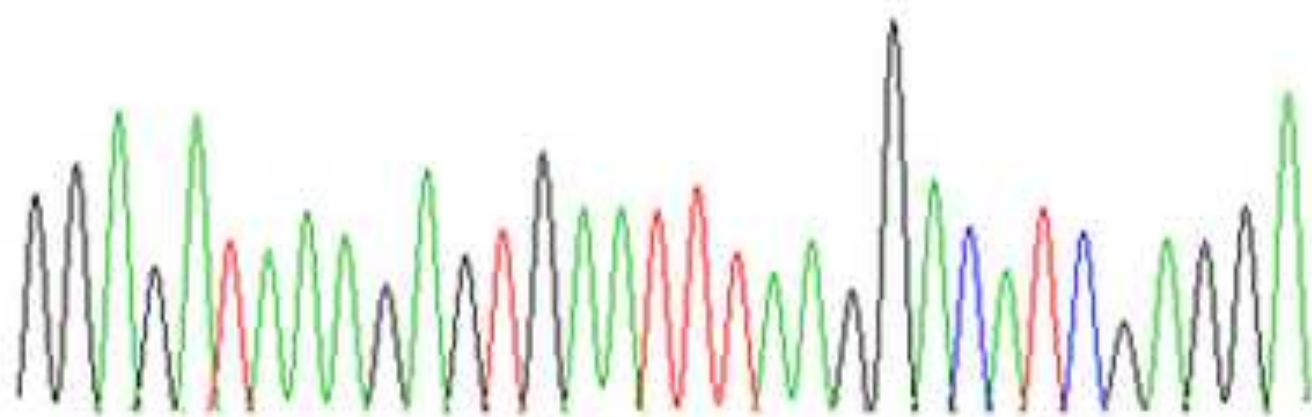

B

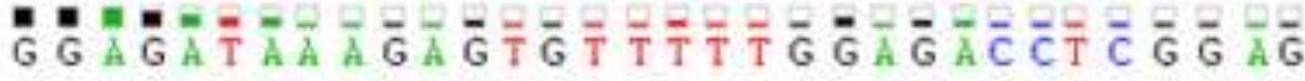

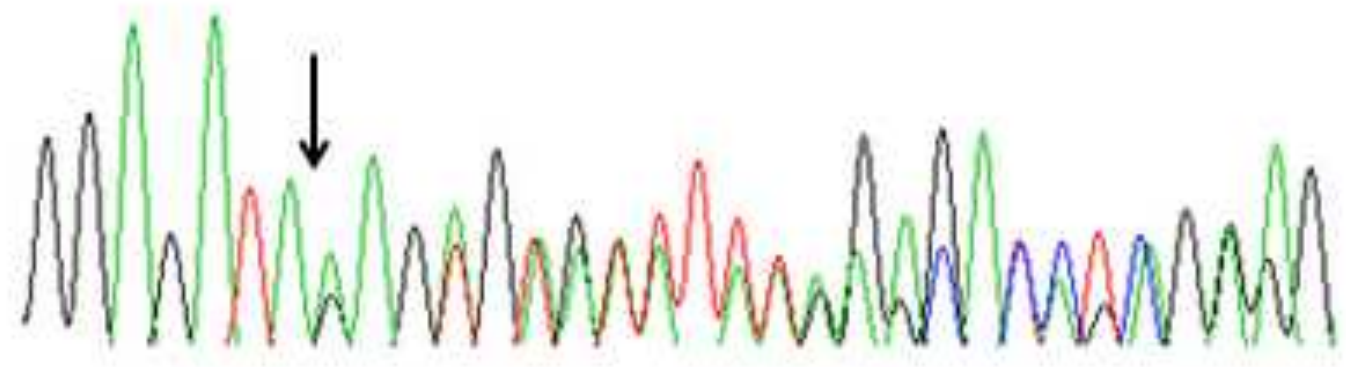

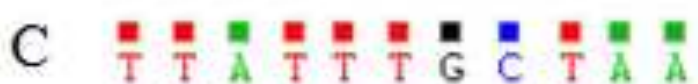

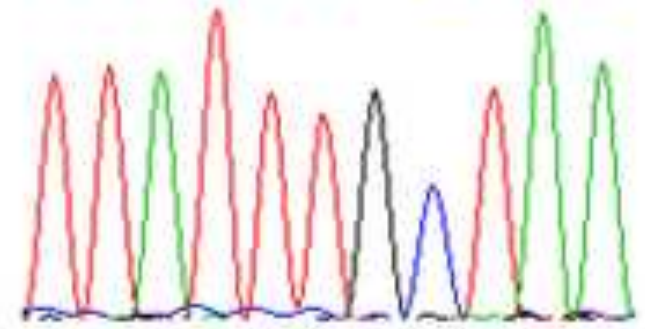

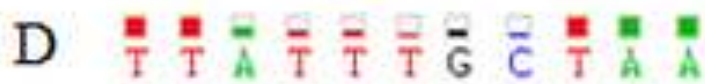

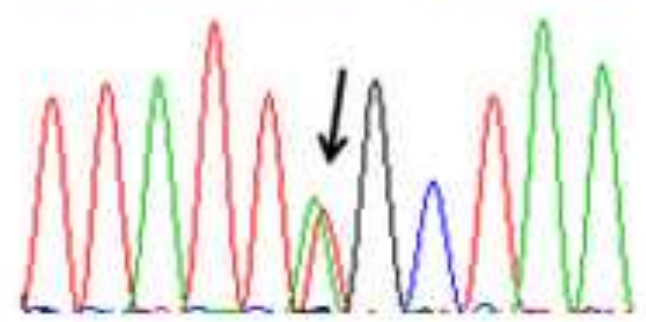




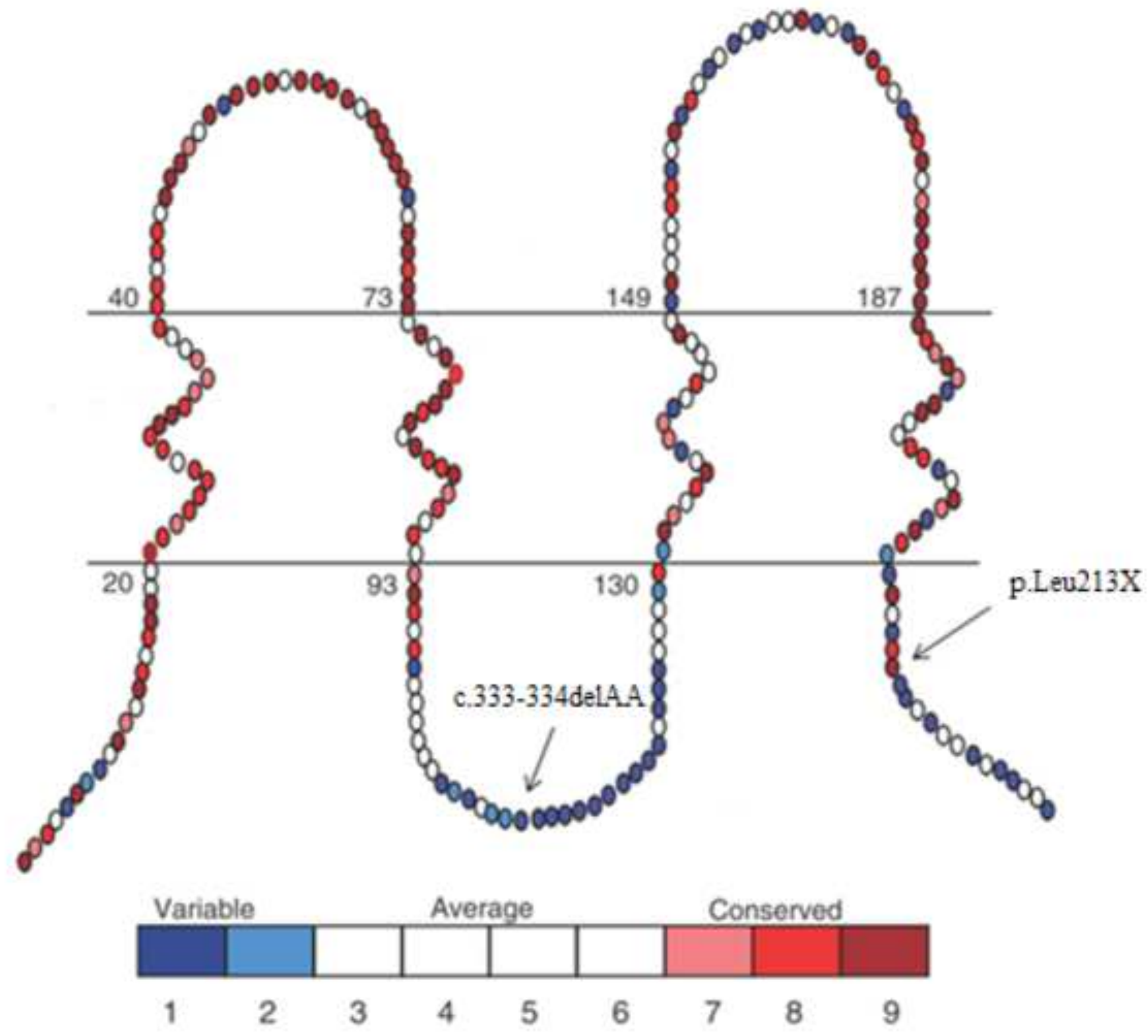

